\title{
Granulocytic Stem Cell (CFUc) Proliferation in Experimental Group B Streptococcal Sepsis
}

\author{
ROBERT D. CHRISTENSEN, ${ }^{(15)}$ HARRY R. HILL, AND GERALD ROTHSTEIN \\ Departments of Pediatrics, Pathology and Internal Medicine, University of Utah School of Medicine and Primary \\ Children's Medical Center, Salt Lake City, Utah, USA
}

\begin{abstract}
Summary
Adult rats infected with group B streptococci (GBS) develop neutrophilia and display a marked increase in granulocytic stem cells (CFUc). In contrast, infected neonatal rats develop a profound neutropenia and their CFUc do not increase. In order to better understand this phenomenon, we assesssed the CFUc proliferative rate in control and infected adult and neonatal rats using the technique of $\left[{ }^{3} \mathrm{H}\right]$-thymidine suicide. Beginning only $3 \mathrm{~h}$ after GBS inoculation, adult rats increased CFUc proliferative activity, as illustrated by an increase in thymidine suicide, from $38 \pm 2 \%$ cell kill in control animals to $70 \pm 2 \%$ when infected (mean + S.E., $P<0.001$ ). In contrast, the CFUc thymidine suicide rate did not increase in infected neonates. It was noted, however, that the baseline CFUc thymidine suicide rate in uninfected neonatal rats exceeded the rate in uninfected adult rats by 2 -3-fold. The CFUc thymidine suicide rate was therefore determined in uninfected premature $(74 \pm 1 \%)$, newborn $(70 \pm 2 \%)$, 1 -wk-old $(70 \pm 1 \%)$, 6 wk-old $(32 \pm 1 \%)$ and 6 -month-old $(37 \pm 3 \%)$ rats. These findings suggest that the proliferative rate of granulocytic stem cells is already maximal or near maximal in noninfected neonatal animals. In contrast to adults, the neonates' granulocyte production from stem cells can not significantly increase, even if bacterial infection is present.
\end{abstract}

\section{Abbreviations}

CFUc, colony forming unit in culture GBS, group B streptococci HBSS, Hank's balanced salt solution PMN, polymorphonuclear leukocyte

The CFUc, or colony forming unit in culture, is an unipotent stem cell capable of giving rise to neutrophil and monocyte/ macrophage cell lines $(2,13)$. During infection in man, CFUc have been observed to increase (12). In experimentally infected adult rats also, the number of CFUc increases to more than three times control values (4). Recently, we have shown that in contrast to adults, neonatal animals do not increase CFUc number during bacterial infection (4). In an attempt to explain this phenomenon, we have used the technique of $\left[{ }^{3} \mathrm{H}\right]$-thymidine suicide (3) to assess the rate of proliferation of CFUc obtained from control and infected adult and newborn rats.

\section{MATERIALS AND METHODS}

Animal Inoculation. Albino Sprague Dawley rats (Simonson Laboratories, Gilroy, CA) were tested at 5 ages: (1) 1 day premature (delivered by hysterotomy 1 day before scheduled, timed delivery, weighing 4-5 g; (2) 4-18 h of life (6-7 g); (3) l-wk-old (14-18 g); (4) 5-6 wk old (73-88 g); and (4) over 6 months old $(375-500 \mathrm{~g})$. One microliter/g body weight of either bacterial, suspension or phosphate buffered saline (PBS) was injected intra- peritoneally using a glass syringe (Hamilton Co., Whittier, CA). Before the injection into adults, the hair of the abdominal wall was clipped and the area was washed with povidone-iodine (Perdue Frederich Co., Norwalk, CT) and 70\% ethyl alcohol.

Type II group B streptococci were isolated from an infected human infant, identified by the precipitin method using rabbit antisera (11), and grown overnight at $37^{\circ} \mathrm{C}$ in Todd-Hewitt broth. After washing with PBS, aliquots were frozen at $-70^{\circ} \mathrm{C}$. Before inoculation into animals, the aliquots were thawed and grown to logarithmic phase in fresh Todd-Hewitt broth. Bacteria were then sedimented by centrifugation and the concentrated organisms were washed three times in PBS. A standard suspension was prepared by diluting the concentrated, washed organisms in PBS to an optical density of 0.9 at $620 \mathrm{~nm}$ (Spectronic 20, Bausch and Lomb, Inc., Rochester, NY). The suspensions were then concentrated or diluted to one of three concentrations: $1 \times 10^{5}, 3 \times 10^{6}$, or $1-2 \times 10^{8}$ colony forming units/microliter.

Blood, peritoneal, and pleural surface cultures from inoculated and control animals were plated onto sheep blood agar and were also grown in Todd-Hewitt broth.

$[$ H]-Thymidine suicide. Thymidine suicide experiments were carried out in a manner similar to that of Byron (3). Bone marrow from the femur of control and infected rats was flushed into HBSS, and counted electronically (Coulter Electronics, Hialea, FL). Marrow cells, $\left(5 \times 10^{6}\right)$, were then placed in each of two plastic tubes. The first tube contained $0.34 \mu \mathrm{g}$ of nonradioactive thymidine in a volume of $1.0 \mathrm{ml}$ HBSS. The second tube contained $0.34 \mu \mathrm{g}$ of thymidine, [methyl ${ }^{3} \mathrm{H}$ ], $0.1 \mathrm{mCi}$, (specific activity 73 $\mathrm{Ci} /$ mmole, New England Nuclear, Boston, MA). The two tubes were then incubated for $20 \mathrm{~min}$ at $37^{\circ} \mathrm{C}$ with agitation every 5 min. Thymidine uptake was then inhibited competitively by adding $30 \mathrm{ml}$ of HBSS containing $10 \%$ fetal calf serum and $100 \mu \mathrm{g} / \mathrm{ml}$ of nonradioactive thymidine. Cell suspensions were then centrifuged at $200 \times g$ for $12 \mathrm{~min}$ and washed twice in the above solution. The cell pellets were then resuspended in McCoy's $5 \mathrm{~A}$ medium (Grand Island Biologicals Co., Grand Island, NY), and counted electronically. Fifty thousand cells were then added to $1.0 \mathrm{ml}$ of McCoy's $5 \mathrm{~A}$ with 200,000 units/liter penicillin and 200 $\mathrm{mg} /$ liter streptomycin, $0.3 \%$ soft agar (Difco Laboratories, Detroit, MI), $15 \%$ fetal calf serum, $3 \%$ postendotoxin serum (obtained from the pooled serum of adult rats $3 \mathrm{~h}$ after intravenous injection of $10 \mu \mathrm{g} / \mathrm{g}$ body weight Salmonella typhosa endotoxin (Difco Laboratories, Detroit, MI) and $0.25 \mu \mathrm{g} / \mathrm{ml}$ nonradioactive thymidine. The mixtures were then plated in $10 \times 35 \mathrm{~mm}$ culture dishes and incubated for 7 days in a $7 \% \mathrm{CO}_{2} 37^{\circ} \mathrm{C}$, high humidity atmosphere (Wedco, Inc., Silver Springs, MD). Colonies of greater than 50 cells were then counted with a stereomicroscope. Colony number in control adult rats ranged from $21-50$ (mean 38.7 )/50,000 plated marrow cells and in control newborns from 17-28 (mean 21.5)/ 50,000 plated marrow cells. Colony formation by cells exposed to $\left[{ }^{3} \mathrm{H}\right]$-thymidine were compared to those exposed to nonradioactive thymidine. In each experiment at least eight replicate culture plates were run. 


\section{RESULTS}

CFUc proliferation in adult rats. Thirty-five 5-6-wk-old rats were inoculated with $3 \times 10^{6}$ type II GBS/g body weight. Blood cultures were positive for GBS when obtained 3-24 h after the inoculation. Peritoneal cultures were positive from $3 \mathrm{~h}$ to 5 days. In spite of positive cultures, all adult animals appeared clinically well within $48 \mathrm{~h}$ after the inoculation. Bone marrow was obtained 3,18 , and $72 \mathrm{~h}$ after GBS or saline inoculation and the CFUc thymidine suicide rate was determined. Figure 1 shows the CFUc thymidine suicide rate (the \% of CFUc that were killed by the radioactive thymidine) in infected and control animals. Three hours after inoculation, the CFUc thymidine suicide rate was markedly increased $(70 \pm 1 \%)$ in the infected animals compared to those inoculated with saline $(38 \pm 2 \% ; P<0.001)$. At $18 \mathrm{~h}$, the CFUc proliferative rate was $33 \pm 1 \%$ in saline-injected and $65 \pm$ $3 \%$ in infected adults $(P<0.001)$, whereas at $72 \mathrm{~h}$ the proliferative rate was $29 \pm 1 \%$ in control versus $49 \pm 2 \%$ in GBS infected animals $(P<0.001)$.

In order to produce a lethal infection, twenty-four 5-6 wk-old adult rats were next inoculated with $1-2 \times 10^{8} \mathrm{GBS} / \mathrm{g}$ body weight (30-60 times the previous dose). Twenty animals died 6-8 $\mathrm{h}$ after the inoculation whereas four survived. The CFUc thymidine suicide rate was assessed in animals inoculated with this higher, lethal dose. Six hours after inoculation the CFUc thymidine suicide rate was $30 \pm 1 \%$ in controls, and $68 \pm 2 \%$ in lethally infected adults $(P<0.001)$; thus, lethal infection, per se, did not affect the increase in CFUc proliferative rate observed in adult animals.

$C F U c$ proliferation in newborn rats. Thirty-eight newborn rats were inoculated with $3 \times 10^{6} \mathrm{GBS} / \mathrm{g}$ body weight; thirty-five died. Postmortem cultures (including blood, pleural surface, peritoneal cavity, liver, and spleen) were all positive for type II GBS. CFUc proliferation in control and GBS-infected neonatal rats was assessed 3 and $10 \mathrm{~h}$ after inoculation. As shown in Figure 2, at $3 \mathrm{~h}$ the CFUc thymidine suicide rate in control neonatal animals was quite high, $(70 \pm 2 \%)$ compared to the control adults. In contrast to infected adults, neonatal animals infected with GBS had CFUc proliferative rates $(65 \pm 2 \%)$ lower than control neonates $(P<$ 0.005 ). At $10 \mathrm{~h}$ the CFUc thymidine suicide rate in controls was $70 \pm 2 \%$ versus $70 \pm 3 \%$ in the infected group. In neonatal animals, CFUc proliferation was already elevated in the noninfected state and was not increased further by the presence of a lethal infection.

We next determined CFUc thymidine suicide rate in neonatal rats with sublethal infection. Twenty-four newborn animals were inoculated with $1 \times 10^{5} \mathrm{GBS} / \mathrm{g}$ body weight (approximately 30 fold fewer organisms/g than in the previous experiment). No

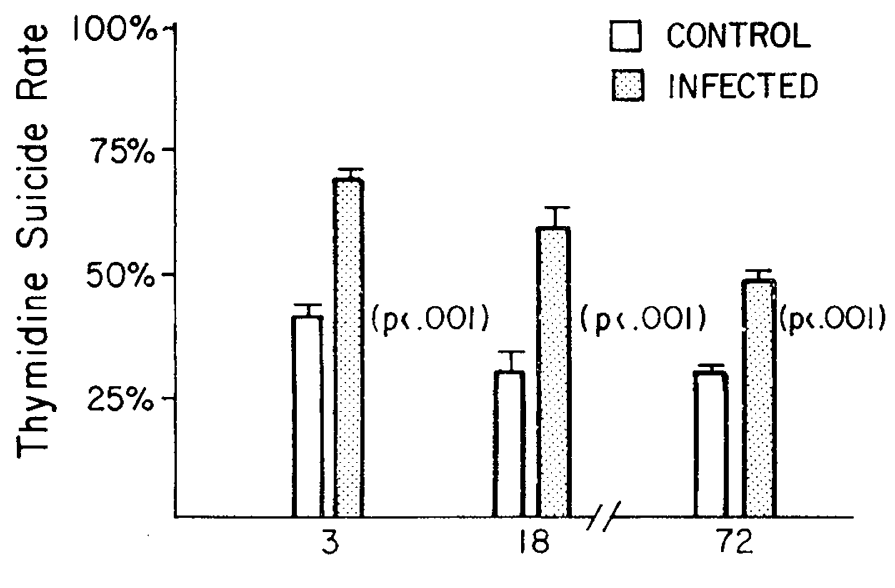

\section{Hours Post Inoculation}

Fig. 1. Granulocytic stem cell (CFUc) proliferative rate, as determined by $\left[{ }^{3} \mathrm{H}\right]$-thymidine suicide, in adult rats, 3,18 , and $72 \mathrm{~h}$ after group $\mathrm{B}$ streptococcal or saline inoculation. Bars represent the mean of 8-10 animals. The bracket indicates the standard error of the mean.

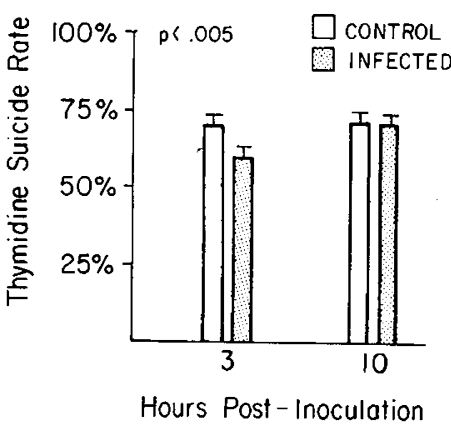

Fig. 2. Granulocytic stem cell (CFUc) proliferative rate, as determined by $\left[{ }^{3} \mathrm{H}\right]$-thymidine suicide, in neonatal rats, 3 and $10 \mathrm{~h}$ after group $\mathrm{B}$ streptococcal or saline inoculation. Bars represent the mean of 8-10 animals. The bracket indicates the standard error of the mean.

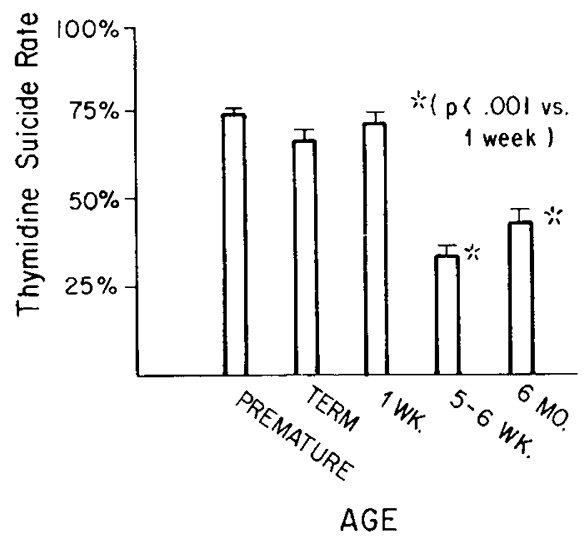

Fig. 3. Granulocytic stem cell (CFUc) proliferative rate, as determined by $\left[{ }^{3} \mathrm{H}\right]$-thymidine suicide, in noninfected rats of various ages. Bars represent the mean of $8-10$ animals. The bracket indicates the standard error of the mean.

deaths resulted. Cultures of blood, peritoneal, and pleural surfaces, however, were all positive for type II GBS $2 \mathrm{~h}$ after the inoculation. By $72 \mathrm{~h}$, cultures were all sterile. Like the neonatal rats with lethal infection, these animals demonstrated a decrease in CFUc proliferative rate when tested $3 \mathrm{~h}$ after the inoculation, $(76 \pm 3 \%$ control versus $45 \pm 5 \%$ infected, $P<0.005$ ). There was, however, a small increase in stem cell proliferation at $15 \mathrm{~h} ; 62 \pm 2 \%$ in controls versus $72 \pm 4 \%$ in the infected group $(P<0.05)$.

$C F U c$ proliferation with advancing age. CFUc proliferation was next assessed in noninfected animals in the following age groups: (1) premature (delivered one day before term); (2) term; (3) $1 \mathrm{wk}$; (4) $6 \mathrm{wk}$; and (5) 6 months. As is shown in Figure 3, CFUc thymidine suicide rates in the preterm, term and 1-wk-old animals were similar and ranged from $68-74 \%$. At 6 wk $(32 \pm 1 \%)$ and 6 months $(37 \pm 3 \%)$ however, CFUc proliferation was considerably lower.

\section{DISCUSSION}

Unlike adults, neonates often develop complete exhaustion of their neutrophil supply during bacterial infection $(1,4,5,6,7,8$, 9). Previous animal studies by our group have demonstrated that neutrophil depletion during infection may result from two factors: (1) the neutrophil storage pool (all PMN, band neutrophils, and metamyelocytes within the bone marrow, liver and spleen) of the premature animal is very small (10) containing less than $1 \times 10^{9}$ cells $/ \mathrm{kg}$ body weight compared to $2 \times 10^{9} / \mathrm{kg}$ in term and $4-5 \times$ $10^{9} / \mathrm{kg}$ in adult rats and (2) the neonates' granulocytic stem cells (CFUc) do not increase during experimental bacterial infection (4) as do CFUc in infected adults $(4,12)$. The inability of neonates to elevate granulocytic stem cell number during infection has 
previously been left unexplained. In the present study, we inoculated adult and newborn rats with group B streptococci or saline and subsequently measured the proportion of their CFUc killed by a flash label of $\left[{ }^{3} \mathrm{H}\right]$-thymidine. As has been demonstrated by Byron (3), CFUc, which are preparing for DNA replication (in the "S" phase of the cell generative cycle), take up thymidine and are killed by the lethal dose of irradiation. Those CFUc that have undergone $\left[{ }^{3} \mathrm{H}\right]$-thymidine suicide cannot subsequently produce granulocyte/macrophage colonies in tissue culture. The CFUc $\left[{ }^{3} \mathrm{H}\right]$-thymidine suicide rate, therefore, measures the proportion of granulocytic stem cells synthesizing DNA and thus, reflects the CFUc proliferative rate.

In the experiments reported here, we have demonstrated that CFUc proliferation is increased 2-3-fold in infected adult rats given a lethal or a sublethal infection. In contrast, infected neonates do not increase CFUc proliferation in response to either a lethal or a sublethal infection. When the CFUc proliferative rate was assessed in noninfected animals at various ages, it was apparent that the baseline rate in normal newborns was actually 2-3 times that of older animals. It seems likely therefore, that a major reason for the lack of increase in CFUc proliferation during bacterial infection is that the neonatal animals' stem cells are already proliferating at a maximal rate. In contrast, the CFUc of adult rats are normally proliferating much more slowly, and a stimulus to increase neutrophil production, such as the presence of bacterial infection, can result in a rapid acceleration of CFUc generative activity and CFUc number.

These observations are compatable with the studies of Erdman and coworkers $(10)$ who demonstrated that within only $36-48 \mathrm{~h}$ in the perinatal period the neonates' neutrophil storage pool doubles in size. In view of this rapid rate of marrow growth, CFUc proliferation would be expected to be considerably greater than in the older, less rapidly growing animal. It seems reasonable then, that the animal whose marrow is growing rapidly may be less able to accelerate neutrophil production during infection and may, therefore, be more suseptible to exhaustion of the neutrophil storage pool with resulting profound neutropenia.

\section{REFERENCES AND NOTES}

1. Armstrong, D., Zeligs, B., and Bellanti, J. A.: The inflammatory response of the neonatal rat to streptococcal infection. Pediatr. Res., 14: 554(A) (1980).

2. Bradley, T. R. and Metcalf, D.: The growth of mouse bone marrow cells in vitro. Aust. J. Exp. Biol. Sci., 44: 287 (1966).

3. Byron, J. W.: Effect of steroids and dibutyryl cyclic AMP on the sensitivity of haemopoietic stem cells to 3H-thymidine in vitro. Nature 234: 39 (1971).

4. Christensen, R. D., Macfarlane, J. L., Taylor, N. L., Hill, H. R., and Rothstein G.: Blood and marrow neutrophils during experimental group streptococcal infection: quantification of the stem cell, proliferative, storage and circulating pools. Pediatr. Res., 16: 549 (1982)

5. Christensen, R. D., Shigeoka, A. O., Hill, H. R., and Rothstein, G.: Circulating and storage neutrophil changes in experimental type II group B streptococcal sepsis. Pediatr. Res., 14: 806 (1980).

6. Christensen, R. D. and Rothstein, G.: Exhaustion of mature marrow neutrophils in neonates with sepsis. J. Pediatr., 96: 316 (1980).

7. Christensen, R. D., Bradley, P. P., and Rothstein, G.: The leukocyte left shift in clinical and experimental neonatal sepsis. J. Pediatr., 98: I0I (198I).

8. Christensen, R. D., Bradley, P. P., Priebat, D. A., Anstall, H. B., and Rothstein, G.: Granulocyte transfusion in septic canine neonates. Pediatr. Res., 16: 57 (1982).

9. Christensen, R. D., Rothstein, G., Anstall, H. B., and Bybee, B.: Granulocyte transfusion in neonates with bacterial infection, neutropenia and depletion of mature marrow neutrophils. Pediatrics, 70: l (1982).

10. Erdman, S. H., Christensen, R. D., Bradley, P. P., and Rothstein, G.: The supply and release of storage neutrophils: A developmental study. Biol. Neonate, 41 . 132 (1982)

11. Lancefield, R. C.: A micro-precipitin technique for classifying hemolytic streptococci and improved methods for producing antisera. Proc. Soc. Exp. Biol. Med., 38: 473 (1938).

12. Metcalf, D.: Hemopoietic Colonies. Recent Results in Cancer Research. p. 83 and 84 (Springer-Verlag, New York, New York 1977).

13. Pike, B. L. and Robinson, W. A.: Human bone marrow colony growth in agar gel. J. Cell Physiol., 76: 77 (1970).

14. The authors thank Jane Macfarlane and Nancy Taylor for technical assistance, and Cleo Ricks for manuscript preparation.

15. Requests for reprints should be addressed to: Dr. Robert D. Christensen, Division of Hematology, University of Utah School of Medicine, 50 North Medical Drive, Salt Lake City, Utah 84132 .

16. Supported by a grant from the Thrasher Research Fund and by Public Health Service grants \#HD-14419, and AI-13150.

17. Received for publication May 11, 1982.

18. Accepted for publication September 9, 1982. 